\title{
A QTL for early heading in wheat cultivar Suwon 92
}

\author{
Xiangyang $\mathrm{Xu}^{1}$, Guihua Bai ${ }^{2, *}$, Brett F. Carver ${ }^{1}$ \& Gregory E. Shaner ${ }^{3}$ \\ ${ }^{1}$ Department of Plant and Soil Sciences, Oklahoma State University, Stillwater, OK 74078, USA, ${ }^{2}$ USDA/ARS \\ Plant Science and Entomology Research Unit, 4008 Throckmorton Hall, Manhattan, KS 66506, USA; ${ }^{3}$ Department \\ of Botany and Plant Pathology, Purdue University, West Lafayette, IN 47907, USA (*author for correspondence: \\ e-mail: guihua.bai@gmprc.ksu.edu)
}

Received 8 May 2005; accepted 8 September 2005

Key words: AFLP, heading date, QTL mapping, SSR, Triticum aestivum

\begin{abstract}
Summary
Heading date is an important trait that determines wheat adaptation to environments. A recombinant inbred line (RIL) population derived from CI $13227 \times$ Suwon 92 was employed to tag the quantitative trait locus (QTL) for early heading in Suwon 92. This population was phenotyped for heading date in 1994, 1995, and 1997, and analyzed with AFLP and SSR markers. Two AFLP markers (XGCTG.CGCT118 and XGCTG.CGCT60) closely associated with heading date were identified. Across years, XGCTG.CGCT118 and XGCTG.CGCT60 explained 40.4\% and $32.2 \%$ of the total phenotypic variances, respectively. Interval analysis revealed a major QTL for heading date, designated QHd.pser-2DS, between AFLP marker XGCTG.CGCT118 and SSR marker Xgwm261. Based on the linkage map, $Q H d$.pser-2DS was about $41.2 \mathrm{cM}$ proximal to the distal end of chromosome 2DS, and explained $40.5 \%$ of the phenotypic variance across three years. The identified markers associated with the early heading QTL have the potential to be used in wheat breeding programs.
\end{abstract}

\section{Introduction}

Understanding the genetic basis of heading date is important for breeding wheat cultivars adapted to diverse environments and to different cropping systems. Three categories of genes influence heading date through their control of photoperiod response $(P p d)$, vernalization response $(V r n)$, and earliness per se $(E p s)$. The $P p d$ and $V r n$ genes interact with environments, whereas Eps genes control developmental rate independently of the environment (Snape et al., 2001; Bullrich et al., 2002).

An orthologous series of photoperiod response genes located on chromosome 2D ( $P p d-D 1$; formerly $P p d 1), 2 \mathrm{~B}$ ( $P p d-B 1$; formerly $P p d 2)$, and 2A (Ppd$A 1$; formerly $P p d 3$ ) play an important role in determining heading date in response to day length, with dominant alleles controlling early heading (Welsh et al., 1973; Law et al., 1978; Scath \& Law, 1983). A previous study demonstrated that $P p d-B 1, P p d-A 1$ and $P p d-D 1$ shortened the heading time by 3,5 , and 8 days, respectively (Scarth \& Law, 1983). Genes on other chromosomes, such as 3D and 4B, also played a minor role in determining day-length response (Miura \& Worland, 1994; Halloran \& Boydell, 1967). Ppd-D1 was located on the short arm of chromosome 2D using genetic stocks (Law et al., 1978) and RFLP markers (Worland et al., 1998), whereas Ppd-BI was mapped on the short arm of chromosome $2 \mathrm{~B}$ in three segregating populations employing AFLP and SSR markers. One AFLP marker linked to $P p d-B I$ was converted to a CAPS marker (Mohler et al., 2004).

Vernalization response genes regulate the requirements of exposure to cold temperatures to induce heading and flowering (Bullrich et al., 2002). Four Vrn genes, namely $V r n-A l$ on chromosome $5 \mathrm{~A}$ (formerly $V r n 1$ ), $V r n-B 1$ on chromosome 5B (formerly $V r n 2$ ), $V r n-D 1$ on chromosome 5D (formerly Vrn3), and Vrn$B 4$ on chromosome 7B, were identified. The Vrn genes have been extensively characterized with molecular markers (Dubcovsky et al., 1998; Nelson et al., 1995; 
Galiba et al., 1995; Iwaki et al., 2002; Toth et al., 2003). High-density genetic maps are available for $\mathrm{Vrn}-\mathrm{Al}$ and $V r n-B l$ regions, and $V r n-A l$ and $V r n-B l$ were successfully cloned through map-based cloning (Yan et al., 2003, 2004).

Earliness per se genes determine the number of vegetative and floral primordia in wheat (Hoogendoorn, 1985). They have received less mapping attention than Ppd and Vrn genes in wheat. Chromosome 2B, 3A, 3D, 4A, 4D, 5A, and 6B (Flood \& Halloran, 1983; Kato et al., 1999; Miura \& Worland, 1994; Miura et al., 1999) were reported to harbour Eps genes/QTLs. Bullrich et al. (2002) identified a major QTL for heading date on chromosome $1 A^{\mathrm{m}}$ of Triticum monococcum. Laurie et al. (1995) reported that most of the chromosomes in barley (Hordeum Vulgare L.) appeared to contain Eps QTLs.

Suwon 92 is a semi-dwarf early maturing Korean wheat cultivar that possesses agronomic features worthy of use in wheat breeding programs (Shaner et al., 1997). Understanding the genetic basis of these traits is helpful for their introgression into commercial cultivars. Here we report the characterization of a QTL for early heading date in Suwon 92 with molecular markers.

\section{Materials and methods}

\section{Experimental materials and design}

A population of 104 recombinant inbred lines (RILs) was developed by single-seed-descent from a cross between Suwon 92 (early heading parent) and CI 13227 (late heading parent) (Shaner et al., 1997). The 104 RILs and two parents were evaluated for heading date at the Agronomy Centre for Research and Education, Purdue University, West Lafayette, IN, in 1994, 1995, and 1997 using a randomized complete block design with two replications. Each experimental line was planted in three $1 \mathrm{~m}$ rows. Natural field conditions in West Lafayette satisfied the vernalization requirements for these RILs. Heading date was recorded as the number of days from 1 January to the date that half of the heads had emerged from flag leaves.

\section{Marker analysis}

Genomic DNA was extracted from two-week old wheat seedlings using the CTAB method (Murray \& Thomposon, 1980). A bulked segregant analysis (BSA)
(Michelmore et al., 1991) was employed to screen informative AFLP primers. Equal amounts of DNA from five early heading RILs were pooled to construct the early heading bulk, while equal amounts of DNA from five late heading RILs were mixed to construct the late heading bulk. The two bulks, together with the two parents, were used to screen informative AFLP primers. Analyses of fluorescence-labeled AFLP and SSR markers were performed using a Li-Cor DNA Analyzer (Li-Cor Inc, Lincoln, NE) (Xu et al., 2005).

\section{Data analysis}

Genetic linkage maps were constructed using MAPMAKER 3.0 (Lander et al., 1987) with a LOD threshold of 4.0. Centimorgan (cM) values were calculated based on the Kosambi mapping function (Kosambi, 1944). Single marker analysis and interval analysis were performed using QGENE software (Nelson, 1997) to determine the effects of each marker and the location of the early heading QTL in Suwon 92. Analysis of variance was conducted using SAS software (SAS Institute Inc., Cary, NC) to estimate broad-sense heritability $\left(\mathrm{H}^{2}\right)$ as the ratio of genetic variance $\left(V_{\mathrm{G}}\right)$ to the total phenotypic variance $\left(V_{\mathrm{P}}\right)$.

\section{Results}

Suwon 92 headed significantly earlier than CI 13227 in all three years (Figure 1). The difference in heading date between the two parents was 7.4 days, 11.5 days, and 5.3 days in 1994, 1995, and 1997, respectively. A continuous distribution for heading date was observed among the RILs, ranging from 167 days (May 16) to

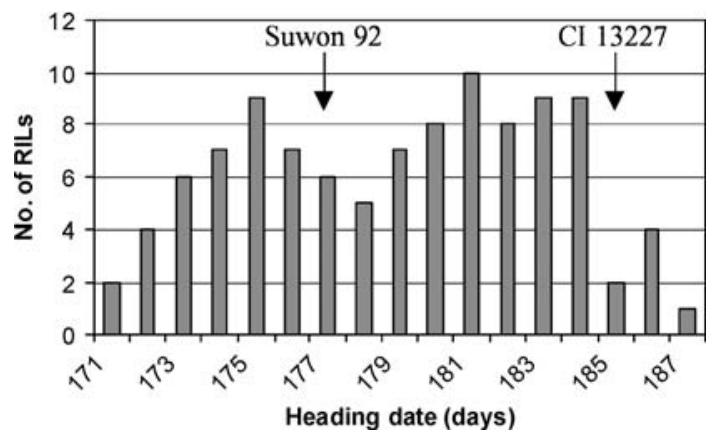

Figure 1. Frequency distribution for heading data across three years for Suwon 92, CI 13227, and RILs derived from CI $13227 \times$ Suwon 92. Heading date was scored from January 1 in each year. 
185 days (June 3) in 1994, 166 days (May 15) to 184 days (June 2) in 1995, and 177 days (May 26) to 196 days (June 14) in 1997. Transgressive segregation was observed in all years.

Correlation coefficients were high for heading date between any pairs of years, ranging from 0.70 to 0.89 and the broad-sense heritability $\left(H^{2}\right)$ was high (0.94). Single marker analysis identified two AFLP markers (XGCTG.CGCT118 and XGCTG.CGCT60) closely associated with early heading date. The genetic distance between them is $3.3 \mathrm{cM}$. Among years, the determination coefficients for markers XGCTG.CGCT118 and XGCTG.CGCT60 ranged from $30.1 \%$ to $40.3 \%$, and $22.0 \%$ to $33.9 \%$, respectively. The additive effects ranged from 2.3 days to 2.9 days for XGCTG.CGCT118, and 2.0 days to 2.6 days for XGCTG.CGCT60 in three years (Table 1). Averaged across years, XGCTG.CGCT118 explained $40.4 \%$ of the phenotypic variance with an additive effect of 2.7 days, whereas XGCTG.CGCT60 explained $32.2 \%$ of the phenotypic variance with an additive effect of 2.4 days. Linkage analysis positioned these two markers on the short arm of chromosome 2D based on the linked SSR markers, Xgwm261, Xbarc95, Xgwm455, and $X$ barc 124, which were previously mapped on chromosome 2DS (Somers et al., 2004; Song et al., 2005).

Interval mapping revealed a major QTL for heading date (Figure 2), designated as QHd.pser-2DS, between AFLP marker XGCTG.CGCT118 and SSR marker Xgwm261 on the short arm of chromosome $2 \mathrm{D}$, with LOD values ranging from 8.5 to 11.1 in three years (Table 2). This QTL explained 39.8\%, 33.5\%, and $32.1 \%$ of the total phenotypic variance in 1994 , 1995, and 1997, respectively. Averaged across years, this QTL resided about $2.6 \mathrm{cM}$ from AFLP marker
XGCTG.CGCT118 and $12.1 \mathrm{cM}$ from SSR marker $X g w m 261$ with a LOD value of 11.4 , and explained $40.5 \%$ of total variance for heading date. Among the SSR markers linked to QHd.pser-2DS, Xbarc124 was previously mapped on the distal end of chromosome 2DS (Somers et al., 2004). Based on the linkage map, QHd.pser-2DS was about $41.2 \mathrm{cM}$ proximal to the distal end of chromosome 2DS.

\section{Discussion}

Worland et al. (1998) located Ppd-Dl on chromosome 2DS, $20.9 \mathrm{cM}$ proximal to $R h t 8$, and the SSR marker Xgwm261 was found to be $0.6 \mathrm{cM}$ away from Rht8 (Korzun et al., 1998). In our study, the QTL QHd.pser-2DS for heading date was also identified on chromosome 2DS. This QTL was $12.1 \mathrm{cM}$ proximal to Xgwm261, and explained about $40 \%$ of the phenotypic variance over three years. It promoted earlier heading by 5-6 days. A previous study also revealed that Xgwm261 was associated with photoperiod response and explained $5.7 \%$ of the phenotypic variance (Sourdille et al., 1999).

Laurie et al. (1995) identified an Eps QTL on chromosome $2(2 \mathrm{H})$ in barley (Hordeum vulgare L.). Although it is reasonable to expect an Eps QTL on wheat chromosome 2DS, such a QTL should have a relatively small effect on heading date (Snape et al., 2001; Kato et al., 1999) and is unlikely to account substantially for the phenotypic variance. Hence, the coincidence of QHd.pser-2DS and Ppdl suggests that Suwon 92 may carry a $P p d l$ gene.

The introgression of genes/QTL for early heading into commercial cultivars to shorten the life cycle of

Table 1. Determination coefficients $\left(R^{2}\right)$, LOD values, $\mathrm{P}$ values, and allelic substitution effects of AFLP markers associated with heading date in 1994,1995 , and 1997

\begin{tabular}{|c|c|c|c|c|c|c|c|}
\hline \multirow[b]{2}{*}{ Year } & \multirow[b]{2}{*}{ Marker } & \multirow[b]{2}{*}{$R^{2}(\%)$} & \multirow[b]{2}{*}{ LOD } & \multirow[b]{2}{*}{$P$} & \multicolumn{2}{|c|}{ Allele mean } & \multirow[b]{2}{*}{ Additive effect } \\
\hline & & & & & CI 13227 & Suwon 92 & \\
\hline & & & & & & - day & - \\
\hline \multirow[t]{2}{*}{1994} & XGCTG.CGCT118 & 40.3 & 11.0 & $<0.0001$ & 29.3 & 23.5 & 2.9 \\
\hline & XGCTG.CGCT60 & 33.9 & 8.7 & $<0.0001$ & 28.7 & 23.5 & 2.6 \\
\hline \multirow[t]{2}{*}{1995} & XGCTG.CGCT118 & 33.9 & 8.8 & $<0.0001$ & 27.4 & 21.6 & 2.9 \\
\hline & XGCTG.CGCT60 & 27.4 & 6.7 & $<0.0001$ & 26.7 & 21.6 & 2.6 \\
\hline \multirow[t]{2}{*}{1997} & XGCTG.CGCT118 & 30.1 & 7.6 & $<0.0001$ & 36.0 & 31.4 & 2.3 \\
\hline & XGCTG.CGCT60 & 22.0 & 5.2 & $<0.0001$ & 35.4 & 31.5 & 2.0 \\
\hline \multirow[t]{2}{*}{ Mean } & XGCTG.CGCT118 & 40.4 & 11.0 & $<0.0001$ & 30.9 & 25.5 & 2.7 \\
\hline & XGCTG.CGCT60 & 32.2 & 8.2 & $<0.0001$ & 30.3 & 25.5 & 2.4 \\
\hline
\end{tabular}


Table 2. Marker intervals, QTL peak positions to the closest marker (QTL peak), determination coefficients, and LOD values for QHd.pser-2DS in Suwon 92

\begin{tabular}{|c|c|c|c|c|}
\hline Year & Interval & $\begin{array}{l}\text { QTL } \\
\text { Peak } \\
(\mathrm{cM})\end{array}$ & $R^{2}(\%)$ & LOD \\
\hline 1994 & XGCTG.CGCT118/Xgwm261 & 2.1 & 39.8 & 11.1 \\
\hline 1995 & XGCTG.CGCT118/Xgwm261 & 2.2 & 33.5 & 8.9 \\
\hline 1997 & XGCTG.CGCT118/Xgwm261 & 3.6 & 32.1 & 8.5 \\
\hline Mean & XGCTG.CGCT118/Xgwm261 & 2.6 & 40.5 & 11.4 \\
\hline
\end{tabular}

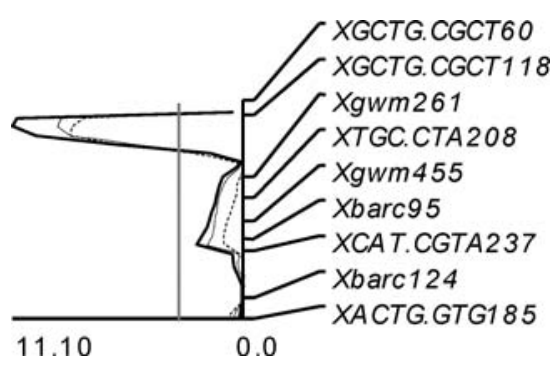

Figure 2. Likelihood plots of a QTL for heading date, QHd.pser2DS. Solid, dot, and slash curves represent results from 1994, 1995, and 1997, respectively. The vertical line represents the threshold LOD value of 3.0. The highest LOD value is given beneath the horizontal line.

wheat is important in most wheat growing areas. In Europe, $P p d-D 1$ typically accelerates flowering time by 6-14 days depending on the growing region (Snape et al., 2001; Worland, 1996), with pleiotropic effects on plant height, tiller number, spikelet number, spikelet fertility, grain filling, kernel weight, and harvest index (Worland, 1996; Foulkes et al., 2004). Its influence on yield is therefore complex and varied in different regions. Snape et al. (2001) reported that genotypes with the photoperiod-insensitivity allele $(P p d-D 1)$ had significantly higher yields in regions with hot, dry summers, whereas genotypes with the sensitive allele ( $p p d-D 1)$ had higher yields in areas with wetter, cooler summers and a longer vegetative growth period.

The early heading QTL, QHd.pser-2DS, should also play an important role in wheat breeding programs, especially in areas where more than one crop is harvested in a year. For example, wheat-maize and wheatrice are popular double-cropping systems in China, where an early harvest is so imperative that early maturity is one of the top breeding objectives. Thus the manipulation of $Q H d$.pser-2DS and other early heading genes/QTL in wheat breeding programs bears agronomic importance. However, PCR-based markers closely linked with early heading genes/QTL are still rare. In this study, the identified QTL, QHd.pser-2DS, was $2.6 \mathrm{cM}$ distal to AFLP marker XGCTG.CGCT118, and $12.1 \mathrm{cM}$ proximal to SSR marker Xgwm261. The successful conversion of the AFLP marker into a STS marker may create a more practical PCR-based marker for marker-assisted selection of QTL QHd.pser-2DS. However, in the absence of a STS marker, SSR marker Xgwm261 is still a useful marker for marker-assisted selection for the QTL. Further fine mapping of this region may identify closer selectable markers to the QTL than Xgwm261.

QHd.pser-2DS explained $40 \%$ of phenotypic variance in three years, leaving a large portion of the variance unexplained. The absence of other detectable QTLs may be partially attributed to the method used in this study. In order to quickly identify molecular markers linked with early heading, we employed the BSA method that assumes that markers polymorphic between the two bulks are associated with the QTLs encoding early heading. The successful identification of linked markers depends on the selection of plants constituting the bulks. Since plant selection was based on phenotypic data, BSA is most effective when recombination does not occur between the target QTL and the flanking markers for the plants selected. If a plant with recombination between the target QTL and the flanking markers is included in one of the bulks, flanking markers will not be detected using this method. Hence, to detect all the QTLs involved, it is necessary to eventually screen the entire genome.

\section{Acknowledgement}

A portion of this research was funded by the Oklahoma Wheat Res. Foundation and the Oklahoma Agric. Exp. Stn. Mention of trade names or commercial products in this article is solely for the purpose of providing specific information and does not imply recommendation or endorsement by the U.S. Department of Agriculture.

\section{References}

Bullrich, L., M.L. Appendino, G. Tranquilli, S. Lewis \& J. Dubcovsky, 2002. Mapping of a thermo-sensitive earliness per se gene on Trticum monococcum chromosome $1 A^{\mathrm{m}}$. Theor Appl Genet 105: 585-593.

Dubcovsky, J., D. Lijavetzky, L. Appendino \& G. Tranquilli, 1998. Comparative RFLP mapping of Triticum monococcum genes 
controlling vernalization requirement. Theor Appl Genet 97: 968-975.

Flood, R.G. \& G.M. Halloran, 1983. The influence of certain chromosomes of hexaploid wheat cultivar Thatcher on time to ear emergence in Chinese Spring. Euphytica 32: 121-124.

Foulkes, M.J., R. Sylvester-Bradley, A.J. Worland \& J.W. Snape, 2004. Effects of aphotoperiod-response gene $P p d-D 1$ on yield potential and drought resistance in UK winter wheat. Euphytica 135: 63-73.

Galiba, G., S.A. Quarrie, J. Sutka, A. Morgounov \& J.W. Snape, 1995. RFLP mapping of the vernalization $(V r n l)$ and frost resistance $(\mathrm{Fr} l)$ genes on chromosome $5 \mathrm{~A}$ of wheat. Theor Appl Genet 90: 1174-1179.

Halloran, G.M. \& C.W. Boydell, 1967. Wheat chromosomes with genes for photoperiodic response. Can J Genet Cytol 19: 394398.

Hoogendorn, C., 1985. A reciprocal F1 analysis of the genetic control of ear emergence, number of leaves and number of spikelets in wheat. Euphytica 34: 545-55.

Iwaki, K., J. Nishida, T. Yanagisawa \& H. Yoshida, 2002. Genetic analysis of $V r n-B 1$ for vernalization requirement by using linked dCAPS markers in bread wheat (Triticum aestivum L.). Theor Appl Genet 104: 571-576.

Kato, K., H. Miura \& S. Sawada, 1999. Detection of an earliness per se quantitative trait locus in the proximal region of wheat chromosome 5AL. Plant Breed 118: 391-394.

Korzun, V., M.S. RÖder, M.W. Ganal, A.J. Worland \& C.N. Law, 1998. Genetic analysis of the dwarfing gene $(R h t 8)$ in wheat. Part I. Molecular mapping of Rht8 on the short arm of chromosome 2D of bread wheat (Triticum aestivum L.). Theor Appl Genet 96: 1104-1109.

Kosambi, D.D., 1944. The estimation of map distances from recombination values. Ann of Eugen 12: 172-175.

Lander, E.S., P. Green, J. Abrahamson, A. Barlow, M.J. Daly, S.E. Lincoln \& I. Newburg, 1987. Mapmaker: an interactive computer package for constructing primary genetic linkage maps of experimental and natural populations. Genomics 1: 174-181.

Laurie, D.A., N. Pratchett, J.H. Bezant \& J.W. Snape, 1995. RFLP mapping of five major genes and eight quantitative trait loci controlling flowering time in a winter $\mathrm{x}$ spring barley (Hordeum vulgare L.) cross. Genome 38: 575-585.

Law, C.N., J. Sutka \& A.J. Worland, 1978. A genetic study of daylength response in wheat. Heredity 41: 185-191.

Michelmore, R.W., I. Paran \& R.V. Kesseli, 1991. Identification of markers linked to disease-resistance genes by bulked segregant analysis: a rapid method to detect markers in specific genomic regions by using segregating populations. Proc Natl Acad Sci USA 88: 9828-9832.

Miura, H., M. Nakagawa \& A.J. Worland, 1999. Control of ear emergence time by chromosome $3 \mathrm{~A}$ of wheat. Plant Breeding 118: $85-87$.

Miura, H. \& A.J. Worland, 1994. Genetic control of vernalization, day length response, and earliness per se by homoeologous group3 chromosomes in wheat. Plant Breed 113: 160-169.
Mohler, V., R. Lukman, S. Ortiz-Islas, M. William, A.J. Worland, J. Van Beem \& G. Wenzel, 2004. Genetic and physical mapping of photoperiod insensitive gene Ppd-B1 in common wheat. Euphytica 138: 33-40.

Murray, M.G. \& W.F. Thompson, 1980. The isolation of high molecular weight plant DNA. Nucleic Acids Res 8: 4321-4325.

Nelson, J.C., 1997. Qgene: Software for maker-based genomic analysis and breeding. Mol Breed 3: 239-245.

Nelson, J.C., M.E. Sorrells, A.E. Van Deyne, Y.H. Lu, M. Atkinson, M. Bernard, P. Leroy, J.D. Faris \& J.A. Anderson, 1995. Molecular mapping of wheat: major genes and rearrangements in homoeologous group 4, 5, and 7. Genetics 141: 721-731.

Scarth, R. \& C.N. Law, 1983. The control of day-length response in wheat by the group 2 chromosome $2 \mathrm{~B}$ of wheat. Heredity 51 : 607-619.

Shaner, G., G. Buechley \& W.E. Nyquist, 1997. Inheritance of latent period of Puccinia recondite in wheat. Crop Sci 37: 748-756.

Snape, J.W., K. Butterworth, E. Whitechurch \& A.J. Worland, 2001. Waiting for fine times: genetics of flowering time in wheat. Euphytica 119: $185-190$.

Somers D.J., P. Isaac \& K. Edwards, 2004. A high-density microsatellite consensus map for bread wheat (Triticum aestivum). Theor Appl Genet 109: 1105-1114.

Song Q.J., J.R. Shi, S. Singh, E.W. Fickus, J.M. Costa, J. Lewis, B.S. Gill, R. Ward \& P.B. Cregan, 2005. Development and mapping of microsatellite (SSR) markers in wheat. Theor Appl Genet 110: $550-560$.

Sourdille, P., J.W. Snape, T. Cadalen, G. Charmet, N. Nakata \& M. Bernard, 1999. Detection of QTLs for heading time and photoperiod response in wheat using a doubled-haploid population. Genome 43: 487-494.

Toth, B., G. Galiba, E. Fehér, J. Sutka \& J.W. Snape, 2003. Mapping genes affecting flowering time and frost resistance on chromosome 5B of wheat. Theor Appl Genet 107: 509-514.

Welsh, J.R., D.L. Keim, B. Pirasteh \& R.D. Richards, 1973. Genetic control of photoperiod response in wheat. In: E.R. Sears \& L.M.S. Sears (Eds.), Proc 4th Int Wheat Genet Symp, pp. 879-884. Agricultural Experimental Station, University of Missouri, Columbia, USA.

Worland, A.J., 1996. The influence of flowering time genes on environmental adaptability in European wheat. Euphytica 89: 49-57.

Worland, A.J., A. Börner, V. Korzun, W.M. Li, S. Petrovíc \& S. J. Sayers, 1998. The influence of photoperiod genes on the adaptability of European winter wheat. Euphytica 100: 385-394.

Xu, X.-Y., G.-H. Bai, B.F. Carver, G.E. Shaner \& R.M. Hunger, 2005. Mapping of QTLs prolonging the latent period of Puccinia triticina infection in wheat. Theor Appl Genet 110: 244-251.

Yan L., A. Loukoianov, A. Blechl, G. Tranquilli, W. Ramakrishna, P. SanMiguel, J.L. Bennetzen, V. Echenique \& J. Dubcovsky, 2004. The wheat $V r n 2$ gene is a flowering repressor down-regulated by vernalization. Science 303: 1640-1644.

Yan L., A. Loukoianov, G. Tranquilli, M. Helguera, T. Fahima \& J. Dubcovsky, 2003. Positional cloning of the wheat vernalization gene VRN1. Proc Natl Acad Sci USA 100: 6263-6268. 